\title{
Ricardo Flores Pedauyé (1947 - 2020)
}

\author{
Vicente Pallás ${ }^{1}$. Francesco Di Serio ${ }^{2}$
}

Published online: 22 October 2021

(c) Società Italiana di Patologia Vegetale (S.I.Pa.V.) 2021

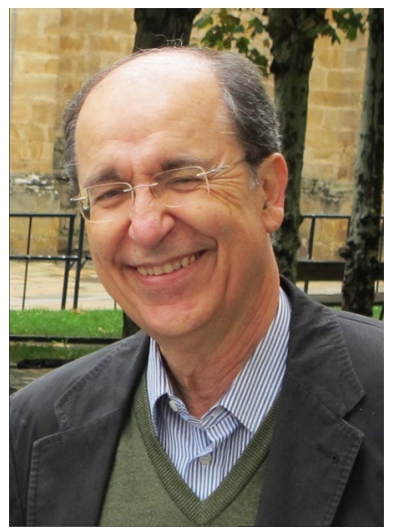

Ricardo Flores Pedauyé, Research Professor ad honorem of the Spanish Research Council (CSIC) at the Institute for Plant Molecular and Cellular Biology (IBMCP) affiliated with both CSIC and the Polytechnic University of Valencia (UPV), Valencia, Spain, passed away on December 20th, 2020. Ricardo was an exceptional scientist, internationally recognized as an authority in the field of plant virology. He dedicated most of his scientific career to the study of viroids, i.e. small infectious RNAs capable of causing plant diseases. We owe him many breakthroughs regarding viroids and their molecular interplay with host plants.

Ricardo Flores graduated in Agricultural Sciences in 1971 and two years later he obtained his degree in Chemistry at the University of Valencia. This unique and rich background was the key of Ricardo's many accomplishments. After obtaining a $\mathrm{PhD}$ degree in 1975, with a dissertation on nucleoproteins associated with citrus tristeza virus (CTV), he became a post-doc in the laboratory of Joseph S. Semancik in Riverside, California, to study citrus exocortis viroid (CEVd), a viroid causing a serious disease to citrus, the most relevant crop in his native Valencia province in Spain. Since then, viroids have been the focus of Ricardo Flores's research. Back in Valencia, he established his laboratory first at the Plant Molecular and Cellular Biology Unit of the Institute

Vicente Pallás

vpallas@ibmcp.upv.es

$\triangle$ Francesco Di Serio

francesco.diserio@ipsp.cnr.it

1 Instituto de Biología Molecular y Celular de Plantas (IBMCP), Universidad Politécnica de Valencia-Consejo Superior de Investigaciones Científicas, Valencia, Spain

2 Consiglio Nazionale delle Ricerche, Istituto per la Protezione Sostenibile delle Piante, Bari, Italy of Agrochemistry and Food Technology (IATA) and then at the IBMCP. Many PhD students and post docs had the opportunity of being involved in multifaceted and complex studies on viroids.

Ricardo Flores' group identified several host enzymes implicated in viroid replication and discovered the mechanisms through which viroids were able to hijack such enzymes for their own purposes. Ricardo notably showed that some of the viroids and viroid-like RNAs he had discovered were able to self-cleave at a specific site in the absence of proteins thanks to "hammerhead" ribozymes. Ultimately, he was interested in addressing evolutionary issues regarding the possible origin of viroids at the origin of life - likely in an RNA world preceding the current cellular-based world. His studies on sequence variability of viroid populations, assessed both in naturally and in experimentally infected hosts, strongly contributed to establish the "quasi-species" nature of these infectious agents and to highlight the in vivo relevance of several conserved RNA structural elements. Issues regarding the structure of viroids were addressed by Ricardo and his research group adopting several experimental approaches, both in vitro and in vivo, and ultimately demonstrated that viroids could accumulate in the infected cells as naked RNAs, not associated with host proteins. Ricardo Flores also studied in depth the role of RNA silencing in plant-viroid interaction, showing that viroids are both triggers and targets of this RNA sequence-specific degradation mechanism and providing evidence that it plays a role in plant-viroid interactions. His work is recognized as being transformative in furthering our understanding not only of viroids but of general aspects of RNA biology. The belief that these tiny infectious RNAs were the source of relevant biological information is masterfully synthesized in a sentences by Pliny the Elder sometimes quoted by Ricardo Flores: "Natura nusquam magis quam in minimis tota est" (In no other place is Nature as a whole as in its smallest creatures).

Ricardo Flores was also dedicated to applied aspects of phytopathological research and he was instrumental in the identification and characterization of many new viroids and 
viroid-like RNAs and of the diseases they are associated with, including grapevine viroids, pear blister canker viroid, apple dimple fruit viroid, peach latent mosaic viroid, chrysanthemum chlorotic mottle viroid, cherry small circular viroid-like RNA 1 and 2. Ricardo Flores was among the promoters of the viroid taxonomy and led the viroid study group of the International Committee on Taxonomy of Viruses that established the classification scheme for viroid classification currently used. In summary, a large part of the knowledge we have today on viroids was spearheaded by Ricardo Flores.

In collaboration with several friend and colleagues, such as Drs. P. Moreno and L. Peña, Ricardo Flores also contributed to increase the knowledge on viruses, mainly citrus tristeza virus, clarifying several aspects related to viral pathogenesis and citrus resistance against this virus.

Ricardo Flores was a fantastic teacher and mentor. Nineteen $\mathrm{PhD}$ students were lucky to have him as a guide during their doctoral studies. Many other students and post docs from Spain and abroad, especially from Italy (the so-called Italian "colony"), had a chance to work in his laboratory and enjoy his culture as well as his enthusiasm for transmitting knowledge.
He got many recognitions, including the honorary membership of the Hungarian Academy of Science. He was elected Vicepresident of the Spanish Society for Virology (and recipient of its biannual prize) and received a Plaque of Honor from the Spanish Association of Scientists.

Ricardo Flores served as associate editor for several international journals, including the Journal of Plant Pathology. He addressed this task with enthusiasm, generosity and always trying to help the youngest researchers to get proper recognition for their work.

Ricardo will be always remembered as an outstanding and brilliant scientist, a rigorous researcher, a generous mentor and a tireless worker. He was very much appreciated for being a real gentleman and a sincere and good friend. Together with his wife Marita, his daughter Maria, his son Ricky, and his grandchildren, all the scientific community will miss Ricardo Flores.

Publisher's Note Springer Nature remains neutral with regard to jurisdictional claims in published maps and institutional affiliations. 